\title{
Relationships Among Senior High Vocational School Teacher Teaching Beliefs, Self-Efficacy, Gender, and School Type
}

\author{
Su-ching Lin \\ Dept. of Education, National Changhua University of Education \\ 1, Jin De Road, Paisha Village, Changhua 500, Taiwan \\ Tel: 886-47232105\# 5701. E-mail: sclin@cc.ncue.edu.tw \\ Shu-Li Chao \\ Da Der Commercial and Technical Vocational School
}

No.277, Sec. 2, Zhongnan Rd., Tianzhong Township, Changhua County 520, Taiwan

Tel: 886-48753929\# 118. E-mail: dt1345@tdvs.chc.edu.tw

Received: August 10, 2014 Accepted: August 30, 2014 Published: August 31, 2014

doi:10.5296/jsss.v2i1.6242 URL: http://dx.doi.org/10.5296/jsss.v2i1.6242

\begin{abstract}
This study investigated the relationships between teacher's teaching beliefs (TB), Self-efficacy (SE), gender, and school type. Descriptive statistics, independent sample $t$-test, and multiple regression analysis were applied to analyze the data. The findings from the Taiwan teacher samples indicated that female teachers had more positive teaching beliefs than male teachers in the teacher-student relationship and overall dimensions. Private school teachers had higher perceived self-efficacy than public school counterparts in community involvement, teacher's role and overall dimensions. The findings of multiple regressions indicated that TB could predict perceived SE. At effective professional training level, teacher perceptions of SE were significantly associated with dimensions of teaching material and strategy, teacher-student relationship, and teacher role. Teaching material and strategy dimension was apparently the best predictor of perceived SE. At good teacher-student relationship level, teacher-student relationship was apparently the best predictor of perceived SE. At positive classroom climate level, teacher role was apparently the best predictor of perceived SE.
\end{abstract}

Keywords: Gender, School type, Self-efficacy, Teaching beliefs, Vocational senior high school teacher 


\section{Introduction}

Beliefs have been described as primers for action, i.e. they influence how individuals react to a situation, what choices they make, and what strategies they adopt. In the daily practice of teaching, beliefs play a significant role inshaping teachers' instructions (Belo, van Driel, van Veen, Verloop, 2014; Mahlios, Shaw, \& Barry, 2010; Löfström, Poom-Valickis, 2012). Teachers' teaching beliefs are assumed to be interconnected and to act as filters through which innovative instructional practices, curricular projects, and contents are assessed, selected and implemented and offer significant promise for exploring the underlying mechanisms that may be related to teachers' decisions to persist in the profession (Fonseca, Costa, Lencastre, \& Tavares, 2012; Lavigne, 2014; Wallace \& Kang, 2004). A large body of evidence from various countries shows that the beliefs of teachers significantly influence how they plan, organize, and implement their lessons and how responsive they are to their students (Leonard \& Leonard, 2006; Staub \& Stern, 2002; Stipek, Givvin, Salmon, \& MacGyvers, 2001).

Teacher efficacy research has been divided into two strands. One is the RAND strand has commonly divided teacher efficacy into the dimensions of General and personal teacher efficacy. The general teacher efficacy refers to teachers' beliefs about how teachers in general can influence on student learning whereas personal teacher efficacy is a more individual and specific belief about the efficacy of their own teaching. The second strand of teacher efficacy research, sometimes called the Bandura strand, defines teacher efficacy as a type of self-efficacy (Malinen \& Savolainen, 2012). The present study follows Bandura's definition of teacher efficacy as a type of self-efficacy. Studies conducted in various national contexts have shown that teachers' perceived self-efficacy, defined as teachers' perceptions of their own ability to bring about desired student outcomes, are a critical factor in the improvement of teaching and student learning (Caprara, Barbaranelli, Steca, \& Malone, 2006; Geijsel, Sleegers, Stoel, \& Krüger, 2009; Takahashi, 2011; Tschannen-Moran \& Woolfolk Hoy, 1998). Teachers' perceived self-efficacy influence the amount of effort teachers put into teaching, their willingness to adopt new teaching strategies, and their ability to persevere in the face of challenges (Bandura, 1997). More specifically, their teaching beliefs may be better able to change their self-efficacy for teaching or efficacious teachers may be better able to change their teaching beliefs in order to accommodate student needs. In other words, there may be a relationship between a teacher's self-efficacy for teaching and teaching beliefs.

Teacher teaching beliefs and self-efficacy are context-specific. Either teacher's teaching belief or perceived teaching efficacy is complex constructs that varies throughout a teacher's career and interacts with teaching environments, such as school type. According to Takahashi (2011), sociocultural theories frame the social environment as an inextricable part of individuals' identities and understandings. Instead of seeing the environmental context as outside of and separate from individuals, this theoretical perspective considers context as both constituting and constituted by individuals. Teachers may feel efficacious for teaching certain subjects to certain students in certain settings while perceiving themselves as less efficacious under different circumstances (Malinen \& Savolainen, 2012; Tschannen-Moran \& 
Woolfolk Hoy, 2007). The effect of various demographic and contextual factors on teacher self-efficacy has also been studied (Skaalvik \& Skaalvik, 2010;Tschannen-Moran \& Woolfolk Hoy, 1998). As mentioned, teacher teaching beliefs and self-efficacy are context-specific. This study will examine the relationship between teachers' beliefs and perceived self-efficacy, including understanding whether gender and school type affect teachers' beliefs and perceived self-efficacy in Taiwan context. The findings are expected to provide valuable information in this field and to enhance understanding of teachers' teaching beliefs and self-efficacy in different cultural contexts.

\section{Methodology}

\subsection{Participants}

Five hundred vocational senior high school teachers from central Taiwan were selected to complete teacher teaching beliefs (TB) and self-efficacy (SE) questionnaires. To ensure confidentiality, each questionnaire was completed anonymously. With a response rate of $96.6 \%, 483$ teachers returned completed questionnaires, including $58.2 \%$ female $(n=281)$ and $41.8 \%$ male $(n=202)$. Of whom, $79.3 \%(n=383)$ taught in public schools and $20.7 \%(n=100)$ taught in private schools.

\subsection{Instruments}

\subsubsection{Perceived TBS}

The Teaching Belief Scale (TBS) developed by the authors on based on the previous study (Ping, 2002), was administered to measure how teachers interpret new knowledge and experiences that may be related to teachers' decisions to persist in the profession by using 20 items in four dimensions, namely, teaching material and strategy, teacher-student relationship, community involvement, and teacher's role. The first dimension, teaching material and strategy (5 items) measured teachers' opinions on teaching content, selection of teaching materials, application of teaching strategies, teaching activity design, and learning assessment. The second dimension, teacher-student relationship (5 items) measured teachers' opinions about students' diversity, teacher-student communication, and classroom management. The third dimension, community involvement (5 items) assessed teachers' opinions related to community involvement, community environment, and school role in the society. The fourth dimension (5 items), teacher role measured teachers' opinions on self-roles and responsibilities. Teachers responded to the items on a five-point Likert scale, ranging from 1 for "strongly disagree" to5 for "strongly agree".

The factor analysis made on data obtained by TBS in the current application reveals that the value of composite reliability is .89 and the value of average variance extracted is .67 , indicating good validity of the items within this scale. The overall internal consistency (Cronbach's $\alpha=.91$ ) for the scale in the current sample was good. The Cronbach's $\alpha$ for the five subscales ranged from .73 to .86 , indicating good internal consistencies of the items within each subscale. 


\subsubsection{Perceived SES}

Another one research instrument, the Perceived Self- Efficacy Scale (SES), was developed by the authors on based on the previous studies (Jeng, 2008) to measure how teachers perceived their own ability to bring about desired student outcome son five dimensions, namely, effective professional training, systematical material organization, multiple teaching strategy, good teacher-student relationship, and positive classroom climate. Twenty-five items in the TES were designed to measure five dimensions. The first dimension, effective professional training (5 items), teachers perceived their professional knowledge can improve their teaching. The second dimensions, systematical material organization (5 items), teachers systematically organized their teaching materials in order to achieve effective teaching. The third dimension, multiple teaching strategies ( 5 items), teachers tried to apply different strategies in order to motivate students to learn actively. The fourth dimension, good teacher-student relationship ( 5 items), teachers concerned about individual student need and often interacted with students in order to build good teacher-student relationship. The fifth dimension, positive classroom climate ( 5 items), a teacher made an offer to create good classroom climate in order to make students learn comfortably. Teachers responded to the items on a five-point Likert scale, ranging from 1 for "strongly disagree" to 5 for "strongly agree".

The factor analysis made on data obtained by SES in the current application reveals that the value of composite reliabilityis .95 and the value of average variance extracted is .81 , indicating good validity of the items within this scale. The overall internal consistency (Cronbach's $\alpha=.95$ ) for the scale in the current sample was good. The Cronbach's $\alpha$ for the five subscales ranged from .76 to .86 , indicating good internal consistencies of the items within each subscale.

\subsection{Data Analysis}

The statistical program SPSS 20.0 for windows was used for data analysis. First of all, four composite scores of teaching material and strategy, teacher-student relationship, community involvement, and teacher's role were computed for each respondent by adding the scores on the $20,5,5,5$, and 5 items in the perceived TB respectively measuring overall, teaching material and strategy, teacher-student relationship, community involvement, and teacher's role. Similarly, a total perceived SE score as well as five additional composite SE scores were computed by adding the scores on the $25,5,5,5$ and 5 items, respectively, measuring total SE, effective professional training, systematical material organization, multiple teaching strategy, good teacher-student relationship, and positive classroom climate. Descriptive statistics and Pearson's product moment correlation coefficients were then computed for all variables in order to examine relationships among teacher gender, school category, perceived TB and SE. In addition, a series of Independent t-tests was used to compare teacher gender (male, female) and school type (public, private) as independent variables on the categories of perceived TB and SE as dependent variables. Finally, regression analysis was used to test with overall TB, effective professional training, systematical material organization, multiple teaching strategy, good teacher-student relationship, and positive classroom climate as dependent variables and 
teachers' gender, school category, and dimension of teaching material and strategy, teacher-student relationship, community involvement, and teacher's role as independent variables to determine if the teacher perceived TB predicted perceived SE.

All statistical tests used to address the questions in this study used .05 as the minimum alpha level. The following tables present some descriptive statistics about variables as well as highlights from the inter-correlations matrix of the variables and the results of the independent sample t-test and multiple regression analysis run in this study.

\section{Results}

\subsection{Difference Analyses in Gender and Schooltype on Teacher TB}

Table 1showed difference analysis results, which indicated that significant differences between male teachers and female teachers in teacher-student relationship $(t=-2.38, p<.05)$ and overall $(t=-1.97, p<.05)$. The significant result indicating female teachers had a higher score on dimensions of teacher-student relationship and overall than male teachers. However, no significant differences were found between male teachers and female teachers in another three dimensions, including teaching material and strategy, community involvement, and teacher role.

Table 1 also indicated a significant difference between teachers who taught in public schools and teachers who taught in private schools in dimensions of community involvement $(t=-2.86$, $p<.01)$, teacher's role $(t=-3.82, p<.01)$ and overall $(t=-2.54, p<.05)$. The significant results indicating teachers who taught in private schools had a higher score on community involvement, teacher's role and overall dimensions than teachers who taught in public schools. In contrast, no significant differences were found between teachers who taught in public schools and teachers who taught in private schools in another two dimensions, including teaching material and strategy, and teacher-student relationship.

Table 1. $t$-tests of gender and schooltype on dimensions of perceived TB $(\mathrm{N}=483)$

\begin{tabular}{lllllllllll}
\hline TB/ & \multicolumn{2}{l}{ male(n=202) } & \multicolumn{2}{c}{ female $(\mathrm{n}=281)$} & \multicolumn{3}{c}{ public(n=383) } & \multicolumn{2}{c}{ private(n=100) } \\
Dimension & $\mathrm{M}$ & $\mathrm{SD}$ & $\mathrm{M}$ & $\mathrm{SD}$ & $t$ & $\mathrm{M}$ & $\mathrm{SD}$ & $\mathrm{M}$ & $\mathrm{SD}$ & $t$ \\
\hline TMS & 4.26 & .49 & 4.33 & .44 & -1.49 & 4.30 & .47 & 4.33 & .46 & -.59 \\
TSR & 4.31 & .47 & 4.41 & .46 & $-2.38^{*}$ & 4.36 & .46 & 4.39 & .47 & -.56 \\
CI & 3.72 & .60 & 3.80 & .55 & -1.55 & 3.73 & .59 & 3.91 & .48 & $-2.86^{* *}$ \\
TR & 3.83 & .51 & 3.89 & .54 & -1.05 & 3.82 & .53 & 4.04 & .48 & $-3.82^{* *}$ \\
overall & 4.03 & .41 & 4.11 & .41 & $-1.97^{*}$ & 4.05 & .41 & 4.17 & .40 & $-2.54^{*}$ \\
\hline
\end{tabular}

Notes: $\mathrm{TMS}=$ teaching material and strategy; $\mathrm{TSR}=$ teacher-student relationship; $\mathrm{CI}=$ community involvement; $\mathrm{TR}=$ teacher role.

${ }^{*} p<.05 .{ }^{*} p<<.01$. 


\subsection{Difference Analyses in Gender and School Type on Perceived SE}

Table 2 showed difference analysis results, which indicated no significant differences were found between male teachers and female teachers in five perceived SE dimensions. In contrast, significant differences were found between public schoolteachers and private school teachers in dimensions of good teacher-student relationship $(t=-1.72, p<.05)$, and positive classroom climate $(t=-2.78, p<.01)$. The significant results indicating the private school teachers had a higher score on these two dimensions than public school teachers.

Table 2. $t$-tests of gender and schooltype on dimensions of perceived SE ( $\mathrm{N}=483)$

\begin{tabular}{llllllllllll}
\hline TE/ & \multicolumn{2}{l}{ male(n=202) } & \multicolumn{3}{c}{ female(n=281) } & \multicolumn{2}{c}{ public(n=383) } & \multicolumn{2}{c}{ private(n=100) } \\
Dimension & $\mathrm{M}$ & $\mathrm{SD}$ & $\mathrm{M}$ & $\mathrm{SD}$ & $t$ & $\mathrm{M}$ & $\mathrm{SD}$ & $\mathrm{M}$ & $\mathrm{SD}$ & $t$ \\
\hline EPT & 4.31 & .48 & 4.34 & .45 & -.19 & 4.32 & .46 & 4.34 & .47 & -.37 \\
SMO & 4.21 & .47 & 4.21 & .50 & -1.18 & 4.20 & .49 & 4.25 & .48 & -.86 \\
MTS & 3.98 & .45 & 4.03 & .48 & -1.19 & 4.00 & .48 & 4.05 & .45 & -.90 \\
GTSR & 4.27 & .46 & 4.33 & .48 & -.28 & 4.28 & .47 & 4.38 & .47 & $-1.72^{*}$ \\
PCC & 4.10 & .50 & 4.12 & .52 & -1.97 & 4.08 & .50 & 4.24 & .53 & $-2.78^{* *}$ \\
overall & 4.17 & .39 & 4.21 & .42 & -.84 & 4.18 & .41 & 4.25 & .41 & -1.59 \\
\hline
\end{tabular}

Notes: $\mathrm{EPT}=$ effective professional training; $\mathrm{SMO}=$ systematical material organization; MTS=multiple teaching strategy; GTSR=good teacher-student relationship; $\mathrm{PCC}=$ positive classroom climate.

${ }^{*} p<.05 .{ }^{* *} p<.01$.

\subsection{The Prediction of Perceived SE From TB}

Table 3 showed the results of regression analyses of the prediction of perceived SE from each dimension of perceived TB. At effective professional training level, teacher perceptions of SE were significantly associated with dimensions of teaching material and strategy, teacher-student relationship, and teacher role. Teaching material and strategy dimension $(\beta=.33 ; p<.001)$ was apparently the best predictor of perceived SE. At teacher-student relationship dimension $(\beta=.18 ; \mathrm{p}<.01)$, and teacher role dimension $(\beta=.16 ; p<.01)$ were also significantly associated with SE. The TB dimensions explained $38 \%$ of the variance in perceived SE at this level $\left(R=.62, R^{2}=.38\right.$, and $\left.F(4,477)=72.62, \mathrm{p}<.001\right)$.

At systematical material organization level, teacher perceptions of SE were significantly associated with dimensions of teaching material and strategy, teacher-student relationship, and teacher role. Dimensions of teaching material and strategy $(\beta=.39 ; p<.001)$ was apparently the best predictors of perceived SE. teacher-student relationship dimension $(\beta=.17$; $p<.001)$ and teacher role dimension $(\beta=.11 ; p<.05)$ were also significantly associated with 
SE. However, pedagogy dimension $(\beta=-.15 ; p<.01)$ was negatively significantly associated with SE at this level. The TB dimensions explained $39 \%$ of the variance in perceived SE at this level $\left(R=.63 ; R^{2}=.39\right.$ and $\left.F(4,477)=76.83, \mathrm{p}<.001\right)$.

At multiple teaching strategy level, teacher perceptions of TB were significantly associated with dimensions of teaching material and strategy, community involvement, and teacher role. The teaching material and strategy dimension $(\beta=.35 ; p<.001)$ was apparently the best predictor of perceived SE. Dimensions of teacher role $(\beta=.22 ; p<.001)$ and community involvement $(\beta=.12 ; p<.05)$ were also significantly associated with SE. The TB dimensions explained $38 \%$ of the variance in perceived SE at this level $\left(R=.62 ; R^{2}=.38\right.$ and $F(4,477)$ $=73.50, \mathrm{p}<.001)$.

Table 3. Multiple regression analyses of dimensions of perceived TB predicting TE at levels of EPT, SMO, and MTS(N=483)

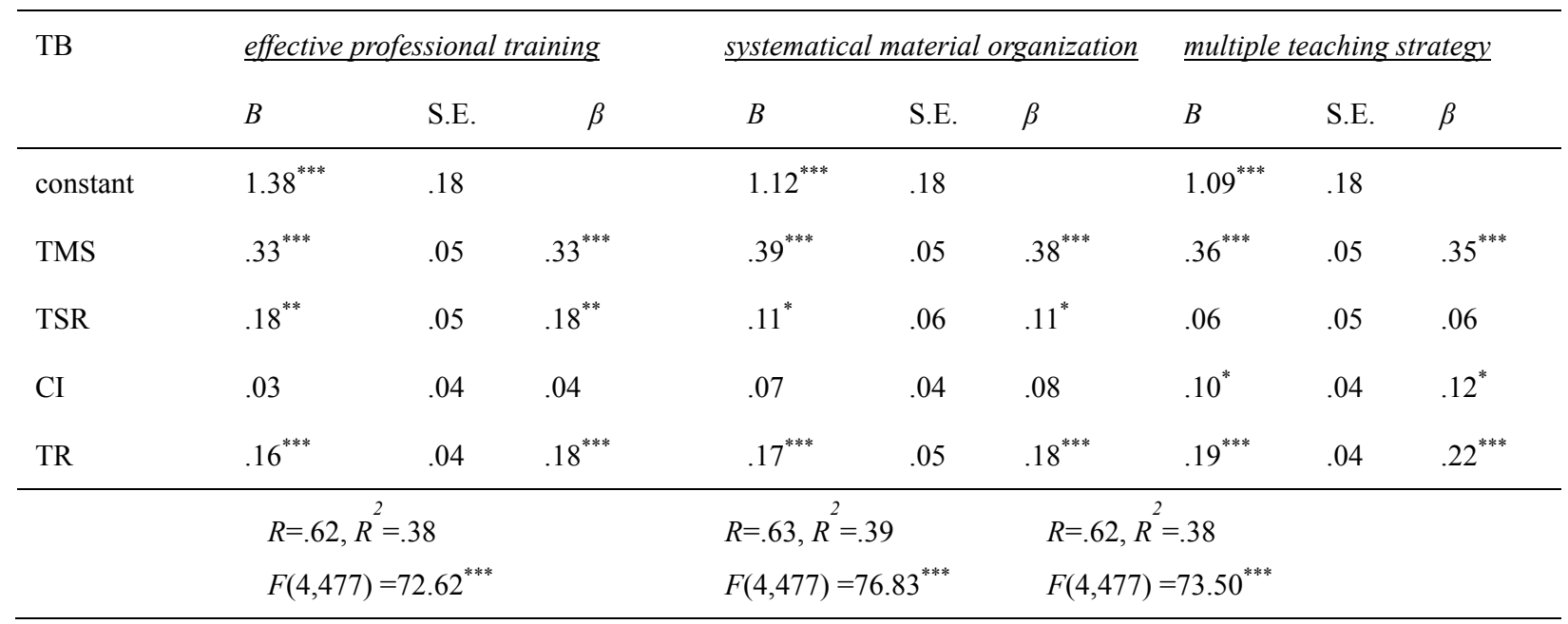

Notes: $\mathrm{TMS}=$ teaching material and strategy; $\mathrm{TSR}=$ teacher-student relationship; $\mathrm{CI}=$ community involvement; $\mathrm{TR}=$ teacher role;

${ }^{*} p<.05$. ${ }^{* *} p<.01$. ***p $<.001$.

Table 4 showed the results of regression analyses of the prediction of perceived SE from each dimension of perceived TB. At good teacher-student relationship level, teacher perceptions of SE were significantly associated with dimensions of teaching material and strategy, teacher-student relationship, and teacher role. Teacher-student relationship dimension $(\beta=.32$; $p<.001$ ) was apparently the best predictor of perceived SE. Dimensions of teaching material and strategy $(\beta=.21 ; p<.001)$ and teacher role $(\beta=.16 ; p<.001)$ were also significantly associated with SE. The TB dimensions explained $38 \%$ of the variance in perceived SE at this level $\left(R=.62, R^{2}=.38\right.$, and $\left.F(4,477)=72.62, p<.001\right)$.

At positive classroom climate level, teacher perceptions of SE were significantly associated with dimensions of teaching material and strategy, community involvement, and teacher role. Teacher role dimension $(\beta=.31 ; p<.001)$ was apparently the best predictor of perceived SE. Dimensions of teaching material and strategy $(\beta=.20 ; p<.001)$ and community involvement 
$(\beta=.11 ; p<.05)$ were also significantly associated with SE. The TB dimensions explained $39 \%$ of the variance in perceived SE at this level $\left(R=.63 ; R^{2}=.39\right.$ and $F(4,477)$ $=76.83, p<.001)$.

At overall level, teacher perceptions of SE were significantly associated with dimensions of teaching material and strategy, teacher-student relationship, community involvement, and teacher role. The teaching material and strategy dimension $(\beta=.34 ; p<.001)$ was apparently the best predictor of perceived SE. Dimensions of teacher role $(\beta=.25 ; p<.001)$, teacher-student relationship $(\beta=.18 ; p<.001)$, and community involvement $(\beta=.10 ; p<.05)$ were also significantly associated with SE. The TB dimensions explained $38 \%$ of the variance in perceived $\mathrm{SE}$ at this level $\left(R=.62 ; R^{2}=.38\right.$ and $\left.F(4,477)=73.50 ; p<.001\right)$.

Table 4. Multiple regression analyses of dimensions of perceived TB predicting TE at levels of GTSR, PCC, and overall ( $\mathrm{N}=483)$

\begin{tabular}{|c|c|c|c|c|c|c|c|c|c|}
\hline \multirow[t]{2}{*}{ TB } & \multicolumn{3}{|c|}{ good teacher-student relationship } & \multicolumn{3}{|c|}{ positive classroom climate } & \multicolumn{3}{|l|}{ overall } \\
\hline & $B$ & S.E. & $\beta$ & $B$ & S.E. & $\beta$ & $B$ & S.E. & $\beta$ \\
\hline constant & $1.21^{* * *}$ & .18 & & $1.12^{* * *}$ & .20 & & $1.19^{* * *}$ & .14 & \\
\hline TMS & $.21^{* * *}$ & .05 & $.21^{* * *}$ & $.22^{* * *}$ & .06 & $.20^{* * *}$ & $.30^{* * *}$ & .04 & $.34^{* * *}$ \\
\hline TSR & $.32^{* * *}$ & .05 & $.32^{* * *}$ & .11 & .06 & .10 & $.16^{* * *}$ & .04 & $.18^{* * *}$ \\
\hline $\mathrm{CI}$ & .04 & .04 & .05 & $.10^{*}$ & .04 & $.11^{*}$ & $.07^{*}$ & .03 & $.10^{*}$ \\
\hline TR & $.16^{* * *}$ & .04 & $.18^{* * *}$ & $.30^{* * *}$ & .05 & $.31^{* * *}$ & $.20^{* * *}$ & .03 & $.25^{* * *}$ \\
\hline \multicolumn{4}{|c|}{$R=.62, R^{2}=.38$} & \multicolumn{2}{|c|}{$R=.63, R^{2}=.39$} & \multicolumn{2}{|c|}{$R=.62, R^{2}=.38$} & & \\
\hline & \multicolumn{3}{|c|}{$F(4,477)=72.62^{* * *}$} & \multicolumn{2}{|c|}{$F(4,477)=76.83^{* * *}$} & \multicolumn{2}{|c|}{$F(4,477)=73.50^{* * *}$} & & \\
\hline
\end{tabular}

Notes: $\mathrm{TMS}=$ teaching material and strategy; TSR=teacher-student relationship; $\mathrm{CI}=$ community involvement; $\mathrm{TR}=$ teacher role;

${ }^{*} p<.05$. ***p $<.001$.

\section{Discussion and Conclusion}

This study explored the relationships among senior high vocational school teacher teaching beliefs (TB), perceived self-efficacy (SE), gender, and school type. The data analysis yielded the following interesting results. First, in TB, the significant result indicating female teachers had a higher score on dimensions of teacher-student relationship and overall than male teachers but no significant differences were found between male teachers and female teachers in perceived SE. This finding supports the studies of demographic variable as an inextricable factor that impacts teachers' beliefs.

Second, a significant difference was found that school type affected the teachers TB and perceived SE. In TBs, the significant results indicating private school teachers had a higher score than public school teachers on community involvement, teacher's role and overall 
dimensions. In SEs, private school teachers also had a higher score than public school teachers on good teacher-student relationship, and positive classroom climate dimensions. The empirical data from Taiwan schools showed that a contextual factor, school type, affected the TB and SE of teachers. In general, private school teachers in Taiwan had a heavier teaching loading and were asked to have more community involvement, more teacher-student interactions and more effective classroom management compared to public school teachers. This might explain why their score higher than public school teachers.

Another interesting finding was TB could significantly predict perceived SE. At effective professional training level, SE was significantly associated with dimensions of teaching material and strategy, teacher-student relationship, and teacher role. Moreover, teaching material and strategy dimension was apparently the best predictor of perceived SE. These findings explored two crucial suggestions for teacher education. First, curriculum design is a very important factor to SE. Teacher education should offer future teachers with curriculum design courses or programs to equip them sufficient knowledge and practice skills to be able to design appropriate curriculum and teaching activities according to different students' learning abilities. Second, both of teacher-student relationship and teacher role were very important to teachers' self-efficacy. Therefore, either preparing future teachers or in-service teachers with professional competences have to emphasize practice skills in building teacher-student relationship and playing good teacher roles. Although the present study only involved one measure of teachers' TB and SE, it could contribute to recent calls for teacher educators to create suitable systems in order to enhance prospective teachers' knowledge and abilities on curriculum design, teacher-student relationship and teachers' roles. Of course, the future research could consider to apply other qualitative measures (e.g., classroom observation, and interviews) to acquire more evidences regarding teachers' beliefs and teachers' self-efficacy.

\section{Acknowledgments}

The authors would like to thank the National Science Council of the Republic of China, Taiwan for financially supporting this research under Contract No. NSC 101-2410-H-018-025-MY2.

\section{References}

Bandura, A. (1997). Self-efficacy: The exercise of control. New York: Freeman.

Belo, N., van Driel, J. H., van Veen, K., \& Verloop, N. (2014). Beyond the dichotomy of teacher- versus student-focused education: A survey study on physics teachers' beliefs about the goals and pedagogy of physics education. Teaching and Teacher Education, 39, 89-101. http://dx.doi.org/10.1016/j.tate.2013.12.008

Caprara, G. V., Barbaranelli, C., Steca, P., \& Malone, P. S. (2006). Teachers' self-efficacy beliefs as determinants of job satisfaction and students' academic achievement: A study at the school level. Journal of School Psychology, 44, 473-490. http://dx.doi.org/10.1016/j.jsp.2006.09.001 
Feng, X.-W. (2002). A study of the relationship between elementary school teachers' teaching beliefs and teaching efficacy (Unpublished Master thesis). National Ping-Tong teacher college, Ping-Tong, Taiwan.

Fonseca, M. J., Costa, P., Lencastre, L., \& Tavares, F. (2012). Disclosing biology teachers' beliefs about biotechnology and biotechnology education. Teaching and Teacher Education, 28, 368-381. http://dx.doi.org/10.1016/j.tate.2011.11.007

Geijsel, F. P., Sleegers, P. J. C., Stoel, R. D., \& Krüger, M. L. (2009). The Effect of Teacher Psychological, School Organizational and Leadership Factors on Teachers' Professional Learning in Dutch Schools. The Elementary School Journal, 109(4), 406-427. http://dx.doi.org/10.1086/593940

Jeng, H. -Y. (2008). A study of the relationship between instructional innovation and teaching effectiveness on vocational high school teachers-Taking knowledge inertia as a moderator (Unpublished Master thesis). National Taichung University of Education, Taichung, Taiwan.

Lavigne, A. L. (2014). Beginning teachers who stay: Beliefs about students. Teaching and Teacher Education, 39, 31-43. http://dx.doi.org/10.1016/j.tate.2013.12.002

Leonard, P., \& Leonard, L. (2006). Teachers and tolerance: discriminating diversity dispositions. The Teacher $\quad$ Educator, 42-62. http://dx.doi.org/10.1080/08878730609555392

Löfström, E., \& Poom-Valickis, K. (2012). Beliefs about teaching: Persistent or malleable? A longitudinal study of prospective student teachers' beliefs. Teaching and Teacher Education, 35, 104-113. http://dx.doi.org/10.1016/j.tate.2013.06.004

Mahlios, M., Shaw, D., \& Barry, A. (2010). Synthesis of metaphors: A review across three studies. Teachers and Teaching: Theory and Practice, 16(1), 49-71. http://dx.doi.org/10.1080/13540600903475645

Malinen, O.-P., Savolainen, H., \& Xu, J. (2012). Beijing in-service teachers' self-efficacy and attitudes towards inclusive education. Teaching and Teacher Education, 28, 526-534. http://dx.doi.org/10.1016/j.tate.2011.12.004

McCall, A. (1995). Constructing conceptions of multicultural teaching: Life experiences and teacher education. Journal of Teacher Education, 46(5), 340-350. http://dx.doi.org/10.1177/0022487195046005004

Montano, T., Lopez-Torres, L., \& DeLissovoy, N. (2002). Teachers as activists: teacher development and alternate sites of learning. Equity \& Excellence in Education, 35(3), 265-275. http://dx.doi.org/10.1080/713845315

Staub, F. C., \& Stern, E. (2002). The nature of teachers' pedagogical content beliefs matters for students' achievement gains: quasi-experimental evidence from elementary mathematics. $\begin{array}{llll}\text { Journal of } \quad \text { Educational } & \text { 344-355. }\end{array}$ http://dx.doi.org/10.1037/0022-0663.94.2.344 


\section{Macrothink}

Journal of Social Science Studies

ISSN 2329-9150

2015, Vol. 2, No. 1

Stipek, D. J., Givvin, K. B., Salmon, J. M., \& MacGyvers, V. L. (2001). Teachers' beliefs and practices related to mathematics instruction. Teaching and Teacher Education, 17, 213-226. http://dx.doi.org/10.1016/S0742-051X(00)00052-4

Takahashi, S. (2011). Co-constructing efficacy: A "communities of practice" perspective on teachers' efficacy beliefs. Teaching and Teacher Education, 27, 732-741. http://dx.doi.org/10.1016/j.tate.2010.12.002

Tschannen-Moran, M., \& Woolfolk Hoy, A. (2007). The differential antecedents of self-efficacy beliefs of novice and experienced teachers. Teaching and Teacher Education, 23, 944 -956. http://dx.doi.org/10.1016/j.tate.2006.05.003

Tschannen-Moran, M., \& Woolfolk Hoy, A. (1998). Teacher efficacy: its meaning and measure. Review of Educational Research, 68(2), 202-248. http://dx.doi.org/10.3102/00346543068002202

Wallace, C. S., \& Kang, N. H. (2004). An investigation of experienced secondary science teachers' beliefs about inquiry: An examination of competing belief sets. Journal of Research in Science Teaching, 41, 936-960. http://dx.doi.org/10.1002/tea.20032

\section{Copyright Disclaimer}

Copyright reserved by the author(s).

This article is an open-access article distributed under the terms and conditions of the Creative Commons Attribution license (http://creativecommons.org/licenses/by/3.0/). 